\title{
QUEM OCUPA CONSTRÓI CONTRACONDUTAS
}

\author{
Marcela Silviano Brandão Lopes ${ }^{1}$ \\ Luciana Souza Bragança ${ }^{2}$ \\ Matheus Silva Coelho ${ }^{3}$ \\ Luiza da Anunciação Guinho ${ }^{4}$
}

DOI: $10.5752 / P .2316-1752.2019 v 26 n 39 p 141$

\begin{abstract}
Resumo
Este artigo pretende discutir sobre as formas de intervenções urbanísticas em territórios socialmente vulneráveis, tendo como referenciais teóricos os conceitos foucaultianos sobre racionalidade neoliberal e contraconduta, e o conceito decolonial sobre pré-existências como forma de resistência. Para fomentar
\end{abstract}

\footnotetext{
1. Graduação em Engenharia Civil pela Universidade Federal de Minas Gerais, Graduação em Arquitetura - Faculdades Metodistas Integradas Isabela Hendrix, mestrado e doutorado em Arquitetura e Urbanismo pela Universidade Federal de Minas Gerais. Professora Adjunta da Escola de Arquitetura da UFMG e Professora colaboradora do Programa de Pós-Graduação- NPGAU. Email: marcelasbl.arq@gmail.com

2. Graduação em Arquitetura e Urbanismo pela Universidade Federal de Minas Gerais, mestrado em Arquitetura e Urbanismo pela Universidade Federal de Minas Gerais, doutoranda em Arquitetura e Urbanismo no Programa NPGAU/ EA UFMG. Professora assistente II do Departamento de Projetos Da Escola de Arquitetura da Universidade Federal de Minas Gerais. Email: lubraganca@gmail.com

3. Graduando em Arquitetura e Urbanismo pela Universidade Federal de Minas Gerais e bolsista de extensão no grupo Indisciplinar/EA-UFMG. Email: matheuscoelho1003@gmail.com

4. Graduando em Arquitetura e Urbanismo pela Universidade Federal de Minas Gerais e bolsista de extensão no grupo Indisciplinar/EA-UFMG. Email: luizaguinho@gmail.com
} 
o debate, será apresentada uma ação extensionista, o Parque das Ocupações, desenvolvida junto a dois projetos de pesquisa e ancorada no reconhecimento das existências de híbridos naturais culturais em curso no território. Subversões metodológicas e epistemológicas foram necessárias para a construção de uma postura não colonial por parte dos envolvidos nessa ação.

Palavras-chave: Ocupações urbanas. Contra condutas. R-existencias. Hibridos naturais culturais. 
WHO OCCUPIES CONSTRUCT COUNTER-CONDUCT

\begin{abstract}
This article intends to discuss the forms of urban interventions in vulnerable territories, having as theoretical references the Foucauldian concepts about neoliberal rationality and counter-conduct and the decolonial concept about pre-existences as a form of resistance. To support the debate, an extension action, Parque das Ocupações, will be presented. It is developed together with two research projects and based on the existence of natural cultural hybrids at the territory. Methodological and epistemological subversions were necessary for the construction of a noncolonial posture from those involved in this action.
\end{abstract}

Keywords: Urban occupations. Conduct.. Cultural natural hybrids.

\section{QUIEN LO OCUPA CONSTRUYE CONTRACON- DUCTOS}

\section{Resumen}

Este artículo pretende discutir las formas de intervención urbana en territorios socialmente vulnerables, teniendo como referencias teóricas los conceptos foucaultianos de racionalidad y contraconducta neoliberal y el concepto descolonial de preexistencias como forma de resistencia. Para estimular el debate, se presentará una acción extensionista, el Parque das Ocupações, desarrollada junto con dos proyectos de investigación, y anclada en el reconocimiento de la existencia de híbridos naturales culturales en el territorio. Las subversiones metodológicas y epistemológicas fueron necesarias para la construcción de una postura no colonial por parte de los involucrados en esta acción .

Palabras-claves: Ocupaciones urbanas. Contra conducta. Híbridos naturales culturales. 


\section{Introdução}

Para a reflexão sobre "Espaços para a Vida" proposta nessa edição dos Cadernos de Arquitetura e Urbanismo da PUC, o presente artigo se debruça no debate sobre processos de intervenções urbanísticas e paisagísticas em territórios socialmente vulneráveis que, na maior parte das vezes, partem de diagnósticos concebidos a partir de problemas e soluções pré-estabelecidos, pautados por evidências físicas e materiais ou mesmo por conceitos sociológicos que, mesmo calcados em pressupostos pedagógicos e participativos bem-intencionados, ignoram os saberes locais. Em outra direção, a proposta apresentada aqui aposta em processos iniciados por mapeamentos das práticas urbanas em curso, a partir dos quais as definições do que sejam potencialidades, fragilidades e principalmente ações serão definidas no encontro dos saberes acadêmicos e dos saberes daqueles que produzem no seu cotidiano os territórios das intervenções.

Para se iniciar a discussão será preciso apresentar o conceito de "racionalidade política" ou "racionalidade governamental", desenvolvido por Michel Foucault (2008). Para o filósofo, a noção "governo" está associada a atividade de reger a conduta dos homens, a partir de técnicas diversas para governar, que atuam em domínios variados, tais como escola, exército, fábrica, etc. Para além de ser uma ideologia ou uma política econômica, trata-se de uma "ra- 
cionalidade", ou seja, de uma atividade de governo que organiza e estrutura a conduta dos homens, por meio de técnicas de dominação exercidas sobre os outros e de técnicas de si.

No que se refere à "racionalidade neoliberal" vigente, Dardot e Laval (2016) afirmam que a concorrência é o seu princípio universal e que o "sujeito empresa" é a figura central dessa racionalidade, um sujeito cujo desejo não é simplesmente afetado pelo apelo do consumo e da competição, mas também produtor de um estar no mundo baseado na eficiência e na acumulação individual. Aparentemente, o novo jogo neoliberal é aberto a todos, bastando aprender as suas regras para entrar nele. Entretanto, tais regras são construídas e legitimadas por meio de dispositivos de poder, que são cada vez mais subordinados à lógica do capital, ou seja, não há aí nenhuma liberdade de fato. Essa mudança afeta de tal maneira o jogo democrático que, segundo esses intelectuais, estamos vivendo atualmente em uma "era pós-democrática". (DARDOT, LAVAL, 2016).

Como possibilidade de se contrapor à racionalidade neoliberal, Dardot e Laval afirmam ser preciso a construção de uma outra razão do mundo - uma "contraconduta", capaz de se apresentar como oposição aos procedimentos de condução postos e como modo de se conduzir em relação aos outros: "a contraconduta como forma de 
resistência a essa governamentalidade [neoliberal] deve corresponder a uma conduta que seja indissociavelmente uma conduta para consigo mesmo e uma conduta para com os outros" (DARDOT e LAVAL, 2016, p. 400).

Vale lembrar que o próprio Foucault (1977) já anunciava a mão-dupla que se estabelece em uma relação de poder: "lá onde há poder há resistência, e, no entanto (ou meIhor, por isso mesmo), esta nunca se encontra em posição de exterioridade em relação ao poder" (FOUCAULT, 1979, p.90). Diante disso, seria possível afirmar que não se trata de se construir algo novo, mas de visibilizar e potencializar práticas que já existem e resistem à revelia dos processos de sujeição neoliberal.

No contexto latino-americano, a colonialidade faz parte do projeto civilizatório da modernidade como forma de poder. A matriz colonial se baseia na naturalização de determinadas hierarquias (territoriais, raciais, epistêmicas, culturais e de gênero). Ao se espacializar, essa forma de poder produz subalternidade e oblitera conhecimentos, experiências e formas de vida daqueles que são dominados (MIGNOLO, 2004. ESCOBAR 2005, 2016). A cidade formal é pensada a partir do colonizador, o que, por sua vez, possibilita a reprodução e a manutenção das relações de dominação ao longo do tempo nas diversas esferas da vida social e essas relações de poder se transformam em espaço. O paradigma do outro, pensamento proposto por 
Mignolo, abre a discussão para o entendimento dos territórios não formais da cidade sob a perspectiva da criação, da possibilidade e da diversidade em contraponto ao espaço moderno aos moldes do colonizador.

Nesse ponto é revelador entender, junto a Stengenr (2002), que o capitalismo nos enfraquece, pois mata os possíveis e também a política, quando nos tolhe o pensamento com a profusão de desejos já prontos e desqualifica o outro como possível construtor do próprio desejo, dialogando, dessa maneira, com o conceito apresentado por Dardot e Laval a respeito da racionalidade neoliberal. Procurar e reafirmar essas outras existências no território é, pois, um ato político de resistência, seja ela confrontativa ou não. Para o autor decolonial argentino Walter Mignolo, a colonialidade moderna não se inscreveu em um espaço vazio de significação, mas, sim, em territórios onde pessoas e natureza se relacionavam e conformavam padrões cognitivos próprios. Por isso, "mais do que resistência, o que se tem é R-Existência, pois não se reage, simplesmente, à ação alheia, mas, sim, que algo pré-existe e é a partir dessa existência que se R-Existe. Existo, logo resisto. R-Existo." (MIGNOLO, 2004).

Com relação ao Brasil, é possível identificar uma r-existência cotidiana, potente e subversiva em várias situações. Nas ocupações urbanas autoconstruídas, por exemplo, essas r-existencias atuam como oposição a uma organi- 
zação fundiária excludente ao transformar um terreno ou edifício que não cumpria sua função social, em um outro, repleto de significações de ordem prática e subjetiva. Essas outras práticas se espacializam mesmo sem uma confrontação direta e são resistentes pela sua existência e constituem territórios e territorialidades.

Dentro dessa perspectiva, as ocupações podem ser entendidas como estratégias territoriais, práticas socioespaciais de resistências/r-existência decoloniais de grupos sociais, ainda que seja uma territorialização precária ou uma forma de escapar da precarização territorial (HAESBAERT, 2009). Importante ressaltar que muitas dessas ações são protagonizadas por mulheres, negras e periféricas, que possuem uma forte presença na organização comunitária das ocupações, mobilizando afetos ligados ao cuidado e ao compartilhamento nas práticas do seu cotidiano.

No intuito de se fomentar o debate, será apresentada a proposta do projeto do Parque das Ocupações, desenvolvida no Programa de Extensão Natureza Política ${ }^{5}$ da UFMG em parceria com o Movimento de Luta dos Bairros, Vilas e Favelas (MLB) ${ }^{6}$, e em associação com

5. Programa de Extensão da Escola de Arquitetura da UFMG. Mais informações ver site: http:// naturezapolitica.indisciplinar.com/

6. Movimento de Luta dos Bairros, Vilas e Favelas. Mais informações ver site: https://www. mlbbrasil.org/our_team 
duas pesquisas: Jardins Possíveis ${ }^{7}$ e Resíduos Sólidos nas Ocupações Urbanas Autoconstruídas ${ }^{8}$. O ponto de convergência do programa e das pesquisas se deu no mapeamento e no reconhecimento de existências e resistências de práticas, que hibridizam natureza e cultura, em um território percebido exclusivamente por meio do conflito legalidade versus ilegalidade ou, ainda, luta por moradia versus área de preservação ambiental. Reconhecer essas existências, para além do conflito, como pistas importantes para a construção de outras condutas e, consequentemente, para a construção de diretrizes urbanísticas, implicou em subversões de ordem metodológica e epistemológica, na busca determinada por uma postura não colonial sobre elas.

\section{Contracondutas acadêmicas}

Diante da necessidade de se construir contracondutas acadêmicas e de reconhecer condutas resistentes e existentes, faz-se urgente propor mudanças teórico-metodológicas na própria universidade. O ponto de referência

\footnotetext{
7. Jardins Possíveis é uma pesquisa de doutoramento, conduzida por Luciana Souza Bragança, financiada pela PRPQ, que busca entender a relação multiespécies na cidade a partir dos jardins. Mais informações: https://jardinspossiveis.wordpress.com/.

8. A pesquisa "Resíduos sólidos nas Ocupações Urbanas Autoconstruídas" é financiada pelo CNPq, por meio do edital 2016/1.
} 
para essa discussão são projetos de pesquisa e de extensão inseridos no campo da produção do espaço em ocupações urbanas autoconstruídas, que buscam se apoiar em pressupostos colaborativos e não autoritários.

A primeira questão proposta aqui se refere à noção de planejamento e projeto associada à solução de problemas. Vale lembrar que, no caso de intervenções urbanas, normalmente o trabalho se inicia com a elaboração de um "Relatório de Diagnóstico", ou seja, com a identificação dos problemas e das demandas no território, os quais são, via de regra, vinculados a critérios e referências pré-definidos. Entretanto, é sabido que as realidades não são dadas exclusivamente pelas estatísticas e mapas oficiais e que a evidenciação de determinados dados em detrimento de outros está sempre associada a valores e interesses que a antecedem. Seria, portanto, pertinente iniciar qualquer processo de intervenção urbanística e arquitetônica a partir da problematização e com a evidenciação das soluções já em curso. Assim, a partir desse mapeamento ampliado, dos acordos entre os envolvidos já territorializados, da equipe técnica e moradores, as estratégias necessárias para as intervenções pretendidas podem ser construídas na junção do saber acadêmico e do saber construído na vivência no território.

Outro ponto importante, ao qual se deve atentar, é sobre a formação dos grupos sociais envolvidos, que não ne- 
cessariamente são grupos coesos, unidos por interesses comuns e com uma forte identidade. Na prática, os interesses não são coletivos todo o tempo e as identidades são várias e difusas, afinal, nenhum grupo de vizinhança é uma comunidade a priori, esse é um processo em constante movimento e transformação (BARTHES, 2003). No caso das ocupações, o sentimento de comunidade é, muitas vezes, acionado a partir da construção coletiva de algum equipamento urbano, que pode funcionar como convocação para um grupo de pessoas se unirem em torno de um objetivo comum, em busca de um sentimento de grupalidade e/ou de pertencimento, mesmo que transitório e em transformação. Entretanto, essa grupalidade é continuamente confrontada com o sentimento real de incerteza da posse da terra e de uma possível e iminente expulsão do território ocupado.

Apesar da importância do uso político do termo "comunidade", é relevante que se tenha um entendimento da real dinâmica dos grupos sociais e não apenas dos grupos socialmente mais pobres, a partir de processos de associações provisórios, seguidos por rupturas e novas composições, em um processo contínuo e não-linear. As marcas deixadas pelas questões de classe são fundamentais para se entender as relações existentes nos territórios pobres, mas elas não esgotam o seu entendimento. Há diferenças de gênero, raça, religião, sexualidade, idade, entre outras que devem ser mapeadas e consideradas. $\mathrm{O}$ 
mapeamento de situações r-existententes vem justamente no sentido de considerar central as pré-existências no território, tomando o mapa como um instrumento político e uma ferramenta representativa que coloca narrativas em evidência, sejam elas hegemônicas, marginais, resistentes ou inventadas, é preciso cartografar e reconhecer narrativas construídas cotidianamente por mais invisibilizadas que elas estejam.

Com relação ao conceito de participação, tão caro aos processos baseados em importantes conceitos sociológicos, muitas vezes ele está baseado na ideia de algo que se concede, idealizado e decidido anteriormente por outra instância e, por isso, passível de controle. Para se pensar em outros modos de fazer junto, vale lembrar do conceito desenvolvido por Roland Barthes (2003) sobre viver junto, associado a uma "aporia de uma partilha da distância", que não se estabelece na homogeneidade, mas "permite várias modalidades de encontro, que se desregula e se engendra na fluidez aleatória dos tempos e dos episódios" (IDEM, p.13).

Por fim, no que tange a relação do projeto arquitetônico com sua execução e gestão, por serem recorrentemente entendidos como etapas distintas e sequenciais, é preciso buscar a aproximação de duas temporalidades distintas, a do projeto relacionada com um tempo futuro e a da execução, que, no caso das ocupações autoconstruí- 
das, muitas vezes coincide com o tempo da urgência e da necessidade. Destaca-se que essa disjunção temporal está relacionada aos preceitos capitalistas, cujo modo de produção das técnicas está baseado em um tempo linear, que busca o controle da produtividade e a eficiência. $\mathrm{O}$ tempo das práticas coletivas não é funcional, nem puramente linear e cronológico, e sim do ato em processo, ou seja, de um planejamento flexível e aberto, atravessado constantemente pelos imprevistos e urgências. O que importa em processos que visam construções coletivas não é exclusivamente se chegar a um produto, mas agregar pessoas em torno de uma ação, em busca de interesses comuns, movidas pela vibração de se construir algo coletivamente.

\section{Quem ocupa, cuida e compartilha}

No contexto do neoliberalismo das grandes cidades brasileiras, vale destacar duas pautas importantes para uma cidade mais justa: a luta pelo direito à moradia e a luta pela preservação ambiental. Entretanto, para muitos, tais questões são divergentes e de difícil conciliação, visto que, quando os elementos naturais não-humanos não são suprimidos da cidade pela lógica formal de urbanização, eles são "protegidos" e concentrados em territórios de pouco acesso ou de usufruto restrito. Entende-se aqui que o real opositor dessas pautas é o capital imobiliário que, sistematicamente, cria justificativas e estratégias 
para fomentar divergências e políticas que excluem e ignoram o outro, seja ele: a natureza, a cultura e, principalmente, a moradia para os pobres inserida na cidade (COSTA, PEIXOTO, 2007). Tal ação se fundamenta e se justifica principalmente no processo de separação dicotômica entre pessoas e natureza e na invenção da natureza empreendida na modernidade e na colonialidade. Reconhecer a alteridade, ou seja, a existência e agência (LATOUR, 2012) de outras culturas, de não-humanos, rompe com essa dicotomia e com essa divergência estratégica e tece possíveis convergências relevantes.

No nosso mundo ocidental, o processo de sedimentação da ideia de uma natureza objetiva e exterior ao humano e a ideia de humano não-natural e fora da natureza ocorreu e se aprofundou principalmente com a industrialização. Esse dualismo se mostra primordial para afirmar a preponderância dos humanos sobre os não-humanos, estes englobados pelo conceito moderno de natureza reforçado pelo colonialismo, para a exploração dos bens naturais. Hissa coloca que a "humanidade do humano é, também, a trágica consciência da invenção moderna da exterioridade da natureza e da exclusão social" (HISSA 2008, p.261). As ações de exclusão se reforçam mutuamente e colocam em campos opostos os elementos não-humanos e os humanos. Tal situação, como explicitado acima, 
enfraquece resistências, tanto ambientais como de moradia, pois promove disputas no campo dos aliados por uma cidade mais justa para todos. Pensar o planejamento e o projeto a partir das r-existências mapeadas no território consideradas conjuntamente, sejam elas de moradia ou ambientais, abre a possibilidade de hibridação das pautas.

Foi buscando contrapor a esse princípio moderno que se iniciou a construção do projeto do "Parque das Ocupações", na região do Barreiro, em Belo Horizonte, Minas Gerais (Fig. 1), em 2015. Considerou-se sua abrangência, desde esse momento, como sendo sobre toda a área de preservação ambiental e sobre todas as ocupações urbanas que estão inseridas no vale. O foco inicial foram as Ocupações Eliana Silva e Paulo Freire, ambas organizadas pelo MLB. 

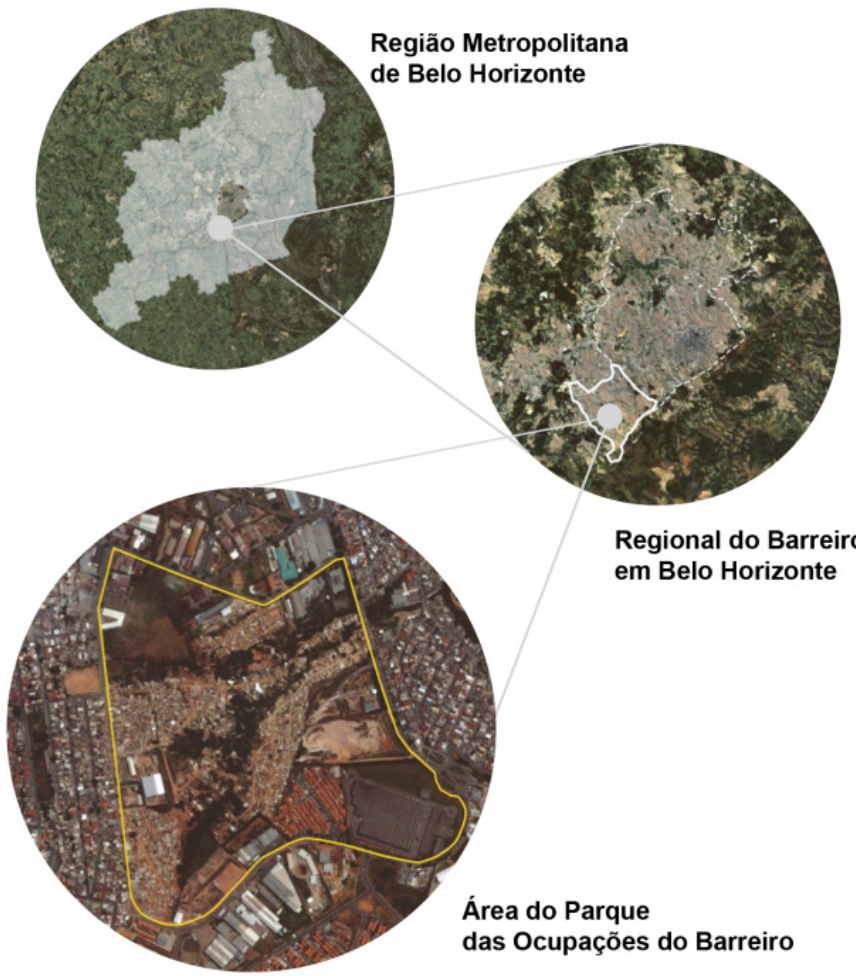

Figura 1 | Localização da área de estudo (parque das ocupações) Fonte: Natureza Política/Indisciplinar/EA-UFMG 
Importante ressaltar que a narrativa de um parque como um devir possível para o Vale das Ocupações foi sendo construída a partir de práticas cotidianas já existentes no território, enfatizando aquelas que eram marcadas pelo cuidado e de apreço pelas plantas, animais, água, como também pela troca e pela compartilhamento, identificável, por exemplo, na coleta e reciclagem de resíduos. Outro ponto importante é que as ocupações do Vale estão em processo de negociação junto ao poder público para regularização fundiária. O objetivo mais amplo é a construção de diretrizes urbanísticas e paisagísticas, a partir de práticas e condutas que são r-existências locais e aproximam moradia e meio ambiente.

A metodologia adotada pelo "Natureza Política" subverte de alguma maneira o percurso adotado nas práticas acadêmicas convencionais, nas quais os parâmetros de qualidade urbanística são definidos a priori para posterior verificação em campo, subsidiando assim as intervenções no território em questão. Em outra direção, a metodologia adotada aqui entende que os parâmetros devam ser construídos na aproximação de saberes e, por isso, incorpora duas etapas. Primeiramente, por meio de cartografias coletivas, busca-se visibilizar tanto os conflitos quanto às soluções já inventadas. Em seguida, é feita a aproximação das invenções cartografadas no território com os conceitos da academia, tais como resistência, ecologia, sustentabilidade, etc. não para confrontá-los, 
mas para buscar possíveis convergências. Tal aproximação é feita com muito critério e rigor, afirmando a existência de outras epistemologias no processo de produção do espaço. Para completar esse processo, a segunda etapa se dá a partir de ações extensionistas que incorporem as r-existências ressignificadas, efetivando intervenções no território que agreguem as possibilidades espaciais locais, além de outras advindas da academia.

Importante ressaltar que esse processo é desenvolvido na articulação entre duas pesquisas e um programa de extensão, o que amplia a pesquisa de campo, na medida em que o território investigado não funciona apenas como local de coleta de dados, mas como espaço vivo de incursões e construção de parcerias. A relação entre pesquisador e pesquisado é também deslocada, ora em direção a troca de saberes e conhecimentos, ora em busca de agenciamentos com o poder público e com atores da iniciativa privada localizada no entorno.

\subsection{Quem ocupa também é natureza}

A pesquisa "Jardins Possíveis" tem o objetivo geral de compreender a relação entre humanos e não-humanos, a partir da perspectiva dos jardins, no sentido de desvelar outras formas de estar na cidade que não as definidas pelo planejamento urbano hegemônico, e de se afastar 
do conceito moderno de natureza. O possível é a chave para identificar e descobrir no território a convivência com a natureza de pessoas que se entendem parte dela, reconhecendo e inventando formas de coexistência no nosso mundo urbano. Nessa busca, a hipótese de trabalho é entender esses espaços r-existentes, especificamente os jardins, e contribuir para pensar a cidade integradamente, pois os jardins são elementos de conexão dos diferentes, de humanos e não-humanos, e constroem uma relação para além das trocas capitalistas no cotidiano.

Na pesquisa o termo jardim é utilizado amplamente e engloba quintais domésticos, espaços públicos plantados coletivamente, além dos espaços de plantio de flores e vasos como eram os jardins no início da colonização. Os jardins são a chave analítica escolhida tanto para a ação extensionista do Parque das Ocupações quanto para a pesquisa. Durante o ano de 2018 e 2019, foram levantados 14 jardins particulares na Paulo Freire e 16 na Eliana Silva, além de 2 hortas comunitárias onde também se cultivam flores, 1 em cada ocupação, 2 nascentes, 1 parquinho e 1 campo de futebol da Paulo Freire. Esses jardins são aqueles que, de alguma forma, as pessoas se engajam pessoalmente e constroem uma relação com os não-humanos, não necessariamente por meio de políticas públicas, e que promovem o encontro e o reconhecimento. Por meio de um mapeamento, baseado na observação participante dos jardins e em entrevistas de caráter 
etnográfico, iniciou-se o entendimento sobre os elementos não-humanos como plantas, animais, água e solo nesse território, e seu relacionamento com os humanos. Os dados apresentados a seguir são preliminares e se baseiam nas entrevistas realizadas pelos pesquisadores.

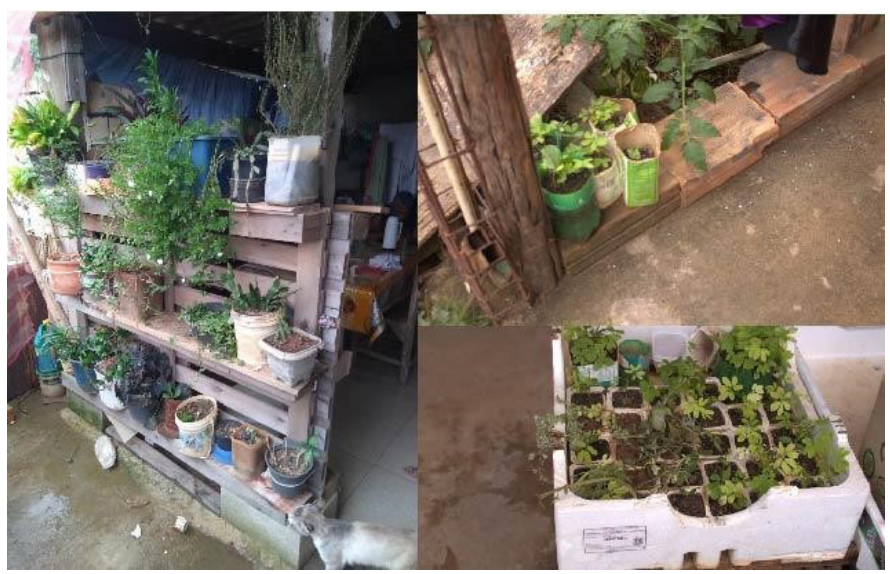

Figura 2 | jardins particulares

Fonte: Natureza Política/Indisciplinar/EA-UFMG (imagens coletadas durante mapeamento realizado na ocupação Paulo Freire em 16/12/2019)

As pessoas que mantém jardins em suas casas o fazem, principalmente, pela sua origem em cidades pequenas e zonas rurais. Esses moradores trazem as memórias dessa vivência cultural. A maioria cultiva flores, verduras, legumes e frutas e criam animais em suas casas ou em áreas coletivas da ocupação. Tendo em vista o ambiente da cidade, o ato de plantar como extensão de sua resi- 
dência evoca um sentimento e uma memória da natureza cotidiana. Além disso, há um sentimento de aproximação e pertencimento que pode ser notado em frases como: "minha vida é natureza" ou "minha amiga aqui [árvore] tá linda".

Ademais, observa-se uma demanda de cultivo para o sustento da família. Há muitos jardins com plantações de ervas para temperos, remédios, misturados a plantas ornamentais, que são cultivados por todos os familiares. Um exemplo disso é um morador de aproximadamente 40 anos, que não só cultiva várias espécies de plantas como também prepara o adubo artesanalmente, com os resíduos orgânicos da própria casa, e mantém uma sucinta criação de abelhas para a polinização do jardim da residência de aproximadamente $18 \mathrm{~m}^{2}$. Além disso, ele constrói uma rede de recebimento de resíduos e distribuição de adubo, fomentando as relações com seus vizinhos, com os animais e plantas. A presença masculina é predominante, mas as mulheres representam $48 \%$.

Pode-se observar também que esse cuidado não é restrito ao ambiente doméstico. Após o plantio da arborização das ruas, promovido pelo Natureza Política em 2018, a maior parte das árvores cuidadas e que sobreviveram estão próximas aos lotes dos jardineiros mapeados. Essa constatação permite inferir que o processo de urbanização das ocupações deva incorporar nas suas diretrizes as práticas cartografadas, inclusive, no que se refere às as- 
sociações que existem no território. Adotar parâmetros urbanísticos que determinam a separação funcionalista e higienista entre não-humanos e humanos seria anular e eliminar práticas potentes presentes ali.

\subsection{Quem ocupa troca}

A pesquisa "Resíduos Sólidos nas Ocupações Urbanas Autoconstruídas ${ }^{9 "}$ é derivada do trabalho de doutoramento de uma das autoras desse artigo, desenvolvido no período entre 2011 e 2015 e que teve sua continuidade por meio do projeto de extensão Artesanias do Comum ${ }^{10}$ . Seu objetivo é o de investigar como e em que medida a prática de coleta e reaproveitamento de resíduos advindos da construção civil se relaciona com conceitos relativos à tecnologia social, sustentabilidade ambiental e cultural e economia solidária.

No processo cartográfico sistematizado em 2019, foi possível identificar tanto as precariedades presentes nas ocupações Eliana Silva e Paulo Freire (Fig. 3) quanto as invenções engendradas pelos moradores, a fim de não se fazer tábula rasa com as soluções em curso. No que diz respeito às precariedades, elas estão presentes tanto na escala do território e da rua (falta de pavimentação,

\footnotetext{
9. Mais informação acessar: https://repositorio.ufmg.br/handle/1843/BUBD-9WRGLR

10. Mais informações, acessar: https://wiki.indisciplinar.com/index.php?title=Projeto_Artesanias_do_Comum
} 
erosões causadas pela chuva, instalações de esgoto precárias, etc) quanto na escala da residência (taludes cortados à $90^{\circ}$, muros de arrimo super ou subdimensionados, infiltrações, janelas e portas sem verga e contraverga e alguns elementos estruturais com problemas construtivos, etc.). Para solucionar ou minimizar os efeitos das precariedades, os moradores criam soluções, que podem ser identificadas tanto no uso compartilhado das ruas por carros, motos, bicicletas e pedestres como em engenhosas soluções construtivas realizadas nas casas e nos espaços coletivos.

Em relação ao material coletado, prática comum nas ocupações autoconstruídas, o mapeamento identificou uma variedade grande (portas, janelas, pallets, madeirites, vasos sanitários, pedras de granito, divisórias, etc.), que é encontrada pelos moradores nas ruas e caçambas das redondezas. Aqueles materiais que estão em melhor estado são procedentes de doações de empresas da região. Esses materiais podem tanto ser utilizados para aquela função que foram produzidos e, não raro, podem ser transformados e ressignificados (Fig. 4), por exemplo um guarda-roupa transformado em vedação, latas de tinta em vasos de plantas e pneus que são usados como contenção, etc. 


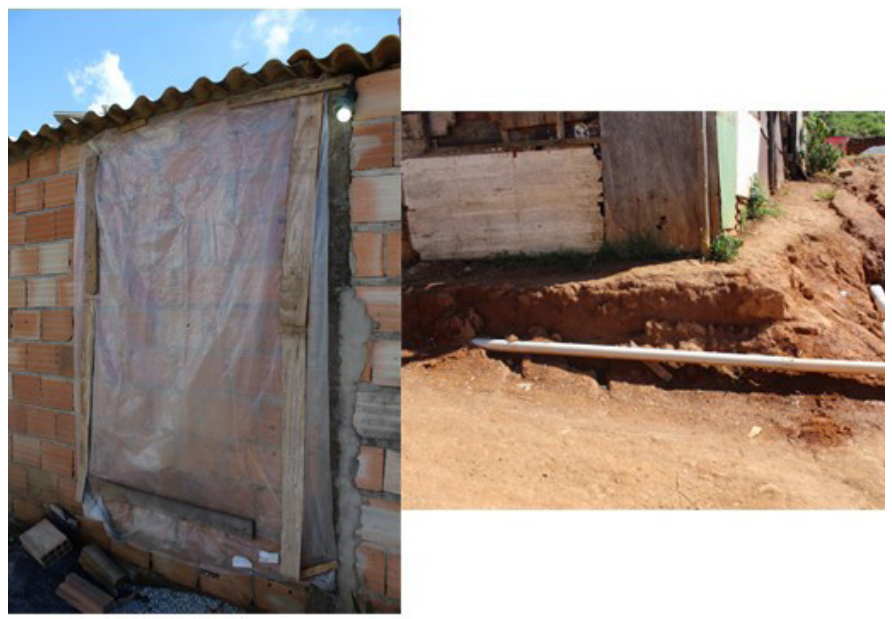

Figura 3 | Precariedades mapeadas no território Fonte: Natureza Política/Indisciplinar/EA-UFMG

(imagens coletadas durante mapeamento realizado na ocupação Paulo Freire em 19/05/2019)

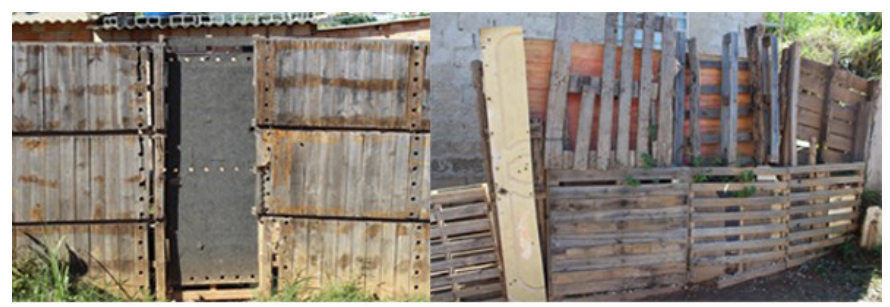

Figura 4 | Inventos mapeados no território

Fonte: Natureza Política/Indisciplinar/EA-UFMG

(imagens coletadas durante mapeamento realizado na ocupação Paulo Freire em 01/06/2019) 
Quanto aos motivos alegados pelos moradores para essa coleta, foram mencionados o uso imediato e também um futuro, configurando nos lotes quase que uma "poupança" dos materiais coletados. Em ambos os casos, esse uso pode ser para demandas próprias e para doação, venda ou troca com algum vizinho. Ou seja, há nas ocupações pesquisadas uma potente rede de economia local baseada nessa coleta de materiais, cujo pressuposto pode até não ser de cunho ambiental, mas as consequências nessa direção são evidentes.

Essa rede nos remete às reflexões feitas por Polanyi (2000) sobre os princípios de comportamento das economias empíricas, a reciprocidade e a redistribuição, baseadas na "ausência da motivação de lucro; a ausência do princípio de trabalhar por uma remuneração; a ausência de qualquer instituição separada e distinta, baseada em motivações econômicas", com garantia de ordem na produção e na distribuição (Polanyi, 2000, p.67). Um outro princípio abordado por Polanyi é o da domesticidade, ou "produção para uso próprio" (Polanyi, 2000, p.70).

Aposta-se que mapear e reconhecer essa rede de troca na sua potência pode contribuir para fortalecê-la, na medida em que o olhar acadêmico pode contribuir para credenciar e legitimar uma conduta econômica que funciona sob pressupostos que não o da acumulação e da competição. Além disso, trata-se de uma prática sustentável não apenas em termos econômicos, mas também 
ambientais, mesmo que esse não seja o intuito de quem coleta e recicla. Em outras palavras, o discurso acadêmico nesse mapeamento pode ter a função de revestir simbolicamente práticas cotidianas consideradas banais, mas que são pistas importantes para a construção de contracondutas capazes de se opor à racionalidade neoliberal vigente, inclusive no planejamento urbano.

Dentro dessa perspectiva, entende-se que a convergência das duas pesquisas pode ser feita por meio de uma cartografia híbrida dos elementos naturais culturais (Fig. 5), assim como de atividades extensionistas.

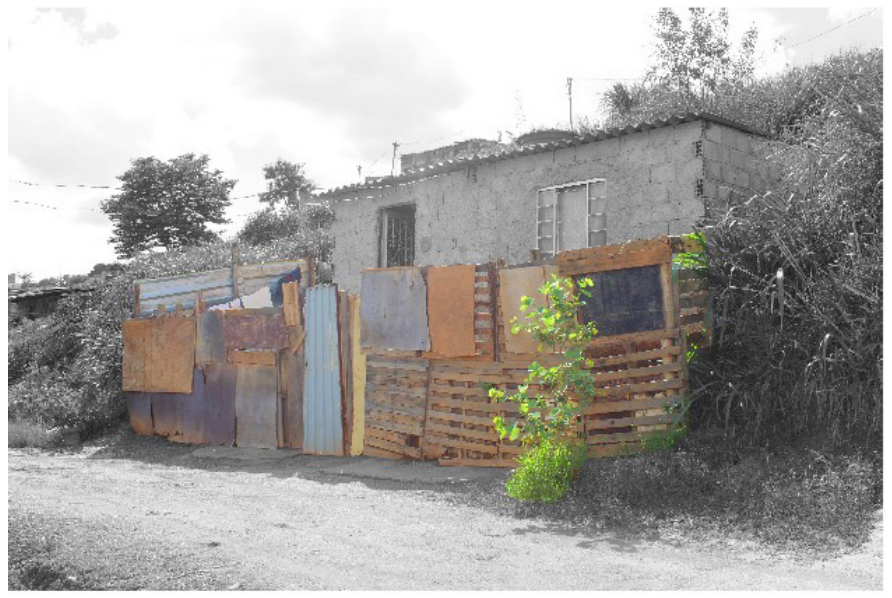

Figura 5 | Edição de figura padronizada de acordo com o inventário natural-cultural, ressaltando os inventos (vedação externa) e a natureza (muda plantada) Fonte: Natureza Política/Indisciplinar/EA-UFMG (imagem coletada durante mapeamento realizado na ocupação Paulo Freire em $16 / 12 / 2019$ 


\section{A extensão como campo de redes e de outras condutas urbanas}

Diante das cartografias realizadas, da visibilização de práticas cotidianas potentes e inventivas, de uma natureza agente, surge para nós, pesquisadores e técnicos, o desafio de construir, junto aos moradores e também para fora das ocupações, estratégias para afirmar os pressupostos da epistemologia local, entendida aqui como um híbrido natural cultural. A proposta desenvolvida no projeto do "Parque das Ocupações", desenvolvida na extensão, incorpora as soluções cartografadas no território, junto às opções construtivas e urbanísticas credenciadas pela academia e pelo saber técnico, num processo de construção mutuamente afetado entre a técnica acadêmica e o território cotidiano.

Ao longo desses anos, por meio de uma rede de parcerias, constituída por atores diversos - moradores das ocupações, coordenação do MLB, poder público por meio de um técnico da COPASA (Companhia de Saneamento de Minas Gerais), empresa vizinha do território por meio do seu departamento socioambiental (VINA) ${ }^{11}$ e universidade, foi possível efetivar diversas ações de plantio no Parque das Ocupações. Importante lembrar dos preceitos da extensão universitária que, além de afirmar a indissociabi-

11. Mais informaçōes acessar: https://vinaec.com.br/socio-ambiental/ 
lidade entre ensino, pesquisa e extensão, objetiva "a interação transformadora entre universidade e outros setores da sociedade." (Fórum de Pró-reitores de Extensão das Universidades Públicas Brasileiras XXVIII Encontro Nacional 2010).

Diante desse princípio, o papel do educador não é o daquele que transfere conhecimento para o educando, visto ainda como aquele que nada sabe. No encontro entre saberes, há de se promover a curiosidade epistemológica e fazer circular a crítica e a criatividade, como nos propõe Paulo Freire. Assim sendo, no projeto Parque das Ocupações, a arborização das ruas e dos espaços coletivos das ocupações tem como proposta a promoção do que se denominou "contra-invasão do verde", no intuito de subverter com humor e ironia o entendimento do senso comum que as pessoas que ali moram são invasoras, oportunistas e destruidoras do meio ambiente.

O processo da arborização também teve início em 2016, com o início do mapeamento da relação dos moradores com a vegetação, a partir do qual foi possível perceber que, apesar da subtração dessa vegetação nas fronteiras entre o território das moradias autoconstruídas e a área de preservação ambiental, as plantas retornavam às ocupações sob a forma de jardins em lugares diversos. Isso ocorre por vários motivos: desde a necessidade alimentar, passando pela composição da renda familiar, ao prazer proporcionado pelos jardins até alcançar a memó- 
ria afetiva associada aos sabores, à beleza e ao cheiros das plantas, além da atração da presença dos animais, principalmente pássaros e borboletas.

Foram, então, desenvolvidas propostas de arborização compostas por árvores da mata nativa para recomposição da mata ciliar e por aquelas identificadas no mapeamento como árvores dos afetos. Foram também incluídas árvores imunes de corte protegidas por lei estadual, chamadas por nós simbolicamente de árvores de resistência, como um "ato de sequestro", cujo refém, a árvore imune ao corte, garantiria também a permanência dos moradores reforçando a possibilidade de resistência conjunta.

Em novembro de 2018, houve uma ação coletiva de arborização das primeiras ruas da ocupação Paulo Freire. A COPASA - em parceria com a ONG Boi Rosado - conseguiu a doação de 80 mudas de diversas espécies: pitanga, pata de vaca, ipês, amora e até um pau Brasil. O departamento socioambiental da VINA doou paliçada, para a drenagem no fundo dos berços cavados, e adubo. À vista de não se tornar apenas uma ação pontual e sem envolvimento dos moradores da ocupação, a equipe do Natureza Política elaborou jogos e uma maquete, no intuito de se fomentar discussões sobre os conflitos potenciais do plantio e de acordar procedimentos e condutas para o cuidado das mudas. O envolvimento dos moradores na atividade preparatória foi intensa, inclusive, com um certo protagonismo das mulheres das ocupações e dos mora- 
dores com jardins já identificados.

O plantio, então, foi realizado nas duas primeiras ruas da ocupação Paulo Freire, respeitando os acordos realizados e conciliando as árvores com a futura instalação dos postes de energia. As árvores foram localizadas na linha divisória dos lotes para evitar futuros conflitos com as construções. Vale apontar que a participação dos moradores no plantio foi muito menor que nas atividades preparatórias e que, novamente, prevaleceu a presença das mulheres e das crianças.

Quanto às práticas de reciclagem, no segundo semestre de 2017, a VINA fez uma doação de um ônibus ao MLB. Em reuniões com todos os integrantes da rede, ficou definido que sua transformação deveria acolher atividades importantes para os moradores das ocupações, tais como realização de feiras, sessões de cinema, além, é lógico, da sua função principal, promover maior mobilidade urbana aos moradores das ocupações organizadas pelo MLB. Por meio de mutirão, alguns bancos internos foram retirados para dar lugar a um novo mobiliário, produzido pelos alunos do Design numa disciplina ministrada por uma das autoras do artigo na Escola de Arquitetura. Nesse mutirão, também houve a instalação de um toldo na lateral externa do ônibus que, quando esticado na horizontal, formaria uma tenda agregando atividades sob ele e, quando esticado verticalmente, funcionaria como uma grande tela de projeção de filmes. 
É curioso observar que nas atividades em torno do projeto arquitetônico para a definição sobre as transformações do ônibus houve uma maior mobilização das mulheres que organizam feiras e festas, bem como das crianças, que se interessam pelos mapeamentos em função do seu caráter lúdico. Já nas atividades de execução das propostas acordadas, o envolvimento maior foi dos homens, seja por conta da força física ou de uma habilidade específica, como foi o caso do serralheiro responsável pela instalação do toldo.

Por fim, houve a alteração estética da carcaça do ônibus, no intuito de se criar uma identidade visual para o coletivo. Palavras foram pintadas, sob a forma de um skyline, nas laterais do ônibus, pelos próprios bolsistas da extensão e da pesquisa, com o apoio dos funcionários da VINA, que também disponibilizou tintas e equipamentos de pintura. Nessa atividade, os moradores do vale das ocupações não participaram, já que na ocasião o MLB havia organizado uma ocupação em um prédio na região central de Belo Horizonte. As definições sobre quais palavras comporiam a identidade do ônibus foram acordadas apenas com a coordenação do movimento, daí, inclusive, surgiu seu nome de batismo: MLBus. Durante o ano de 2018, o ônibus circulou pela cidade, coletando assinaturas para a formação do partido político criado pelo MLB e outros movimentos de luta parceiros, a Unidade Popular pelo socialismo (UP), promovendo bazares e atividades 
de formação política e, claro, levando os moradores às reuniões, manifestações, sessões de cinema no centro.

No início de 2019, no intuito de se fazer um balanço geral das atividades desenvolvidas ao longo dos últimos anos, foi promovida uma reunião com a presença de todos os integrantes da rede de parceiros. Nessa reunião, foram apontados vários problemas mecânicos no MLBus ocorridos em 2018, que poderiam ser evitados se tivesse havido uma manutenção sistemática do veículo. Entendendo as dificuldades do movimento para efetivar a manutenção e a gestão do uso do veículo, a VINA fez uma grande revisão mecânica com as devidas reparações que o veículo necessitava e ofereceu um curso de logística para um integrante do MLB e um curso profissionalizante de mecânica para dois moradores das ocupações, visando, assim, à autonomia do movimento para assuntos técnicos relativos ao funcionamento do ônibus. Destaca-se que, paradoxalmente, a autonomia almejada esteve, em diversos momentos, não totalmente dissociada do risco do estabelecimento de uma relação paternalista entre empresa e movimento social. Havia, pois, um consenso que era preciso atentar para esse risco.

Com objetivo de alinhar as parcerias e fazer uma revisão do processo da construção do Parque das Ocupações uma vez que a dificuldade de mobilização dos moradores para questões coletivas impossibilitava a efetivação de diversas ações de continuidade ao parque -, houve, 
no começo de julho de 2019, uma reunião dos atores envolvidos no projeto (movimento social, extensão universitária, empresa e poder público). Assim, acordou-se a criação de quatro grupos de trabalho para incrementar as atividades de campo: GT mobilização, GT urbanização (drenagem e pavimentação), GT arborização, GT reciclagem de resíduos.

A fim de fomentar a sensibilização sobre a pauta ambiental, o GT mobilização organizou em agosto uma sessão de cinema na Paulo Freire, tendo como temática a agroecologia, seguida de uma roda de conversa. Para atrair os moradores, foi feita canjiquinha e pipoca, com o apoio da VINA na compra dos ingredientes. Apesar do frio e da dificuldade de mobilização, a participação dos moradores foi avaliada pela coordenação dos MLB como sendo significativa.

Como primeira atividade do GT arborização, foi realizada também em agosto uma visita à Ocupação Paulo Freire, no intuito de se fazer uma segunda avaliação das mudas plantadas em novembro de 2018. Constatou-se que algumas mudas tinham morrido, outras estavam disputando espaço com entulhos e materiais de obra, mas muitas haviam sobrevivido e crescido bastante no espaço de tempo de aproximadamente 10 meses. Vale destacar que as árvores que cresceram estavam em frente ou próximas às casas cujos moradores mantém jardins, pois eles estavam cuidando da adubação e rega das mudas. 
Outra ação importante do GT arborização aconteceu no início de setembro, em uma visita à área de preservação localizada entre as ocupações Eliana Silva e Nelson Mandela, na qual foi identificado um cedro de tamanho e idade considerável e foi localizado um poço de criação de peixes, já, inclusive, indicado por moradores na pesquisa "Jardins Possíveis". Nesse dia, foi também feita a coleta de amostras da água das nascentes, para análise laboratorial, cujo resultado acusou a presença de coliformes fecais, ou seja, inapropriado para consumo ou banho. Pela localização da nascente, concluiu-se que a contaminação era consequente, não apenas do esgoto da Eliana Silva, mas também da ausência de rede ampla da COPASA instalada no bairro vizinho localizado a montante do vale das ocupações.

Na sequência, em setembro, os GT's mobilização e arborização organizaram uma trilha pela área de preservação, que contou com a participação de moradores, integrantes do MLB, funcionários da VINA e equipe do Natureza Política. Foi feito o plantio de 2 mudas de ipê na região das nascentes visitadas, acompanhado por um piquenique, abrindo simbolicamente o início da primavera do parque e marcando o entendimento dos ciclos da natureza. Novamente, a maior parte dos moradores participantes foi de mulheres e crianças. 
Com relação às atividades do GT reciclagem de resíduos, no dia da trilha foi proposto aos moradores presentes a realização de uma oficina de reciclagem, a ser oferecida pela designer da VINA e pela equipe do Natureza Política. Naquele dia, houve o interesse de algumas pessoas, na maioria mulheres que já fazem algum tipo de trabalho manual, necessitadas de melhorar a sua renda. Entretanto, ao longo do semestre, essa atividade foi se revelando mais difícil de viabilizar, seja por conta do horário e do local da oficina (aos sábados na sede da empresa), ou do não entendimento entre os proponentes, que discordavam entre si quanto aos métodos e propósitos.

Outra frente de ação coordenada pelo GT reciclagem foi a transformação do container da Ocupação Paulo Freire, naquele momento usado apenas como depósito de doações e outros materiais do movimento, para abrigar novos usos, tais como reuniões, biblioteca, etc. A equipe do Natureza Política produziu uma fotomontagem da nova configuração espacial acordada com os moradores da ocupação (Fig. 6) e, na sequência, houve um mutirão para preparo do local - limpeza do mato, acerto do nível do terreno, etc. 


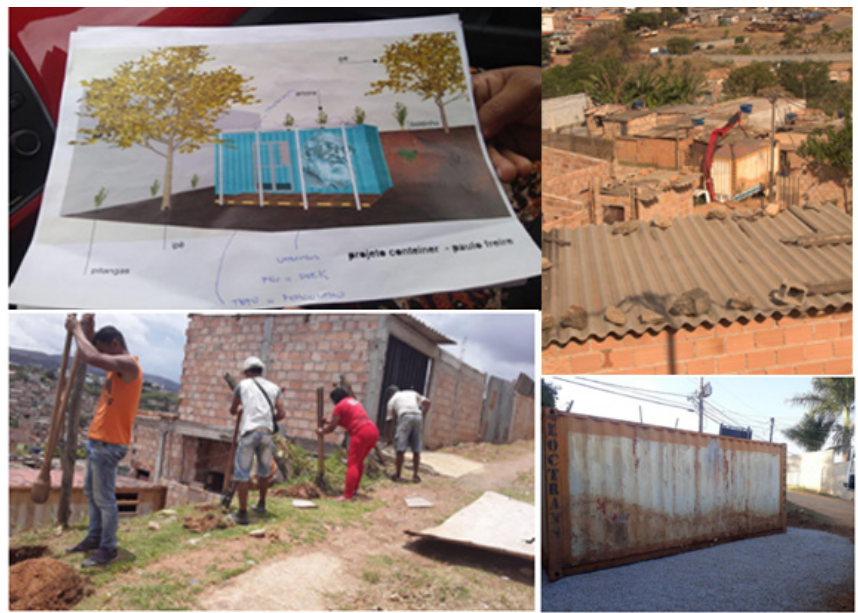

Figura 6 | Fotomontagem, transferência do contêiner na ocupação e mutirão Fonte: Natureza Política/Indisciplinar/EAUFMG

(processo de transferência do contêiner e plantação das mudas realizada em dezembro de 2019)

Por fim, para finalizar as ações de plantio do semestre, foi acordado que no terreno onde foi instalado o container, seriam plantadas mudas de boldinho na encosta a fim de evitar possíveis deslizamento de terra. O boldinho é uma espécie de planta que tem propriedades medicinais e uma conotação religiosa, ligada à matriz africana, iden- 
tificada como elemento de poder nas entrevistas. Também foi decidido que seriam plantadas mudas de amora e pitanga ao longo da divisa do terreno para proporcionar sombra, frutas, presença de pássaros e crianças no entorno do container. Para tal, houve o preparo da encosta por um funcionário da VINA e um mutirão dos moradores para a abertura dos berços das árvores. Apesar da mobilização para essa atividade ter se iniciado com bastante empenho, a sua finalização não aconteceu, em função da realização de outros eventos já agendados pelo movimento (festas de natal, festa da creche Tia Carminha, etc.) e do início do período de chuvas na cidade. Essas atividades estavam programadas para serem retomadas em março de 2020, mas, em razão da pandemia do novo Coronavírus, ela não aconteceu.

As atividades do GT reciclagem seriam retomadas em abril, em duas frentes: reforma do container e oficina de reciclagem do seu mobiliário. Novamente, em função do isolamento social imposto pelo novo vírus, essas atividades ainda não aconteceram. No que diz respeito ao GT urbanização, a articulação entre os integrantes foi mais difícil e as atividades relacionadas à discussão sobre opções para a drenagem e para a pavimentação não aconteceram. Infelizmente, quando vieram as chuvas de janeiro, que no ano de 2020 foram mais intensas que nos anos anteriores, vieram junto os deslizamentos de terra nas encostas, principalmente na Ocupação Paulo Freire. 
Como o poder público não conseguiu atender às demandas de toda a cidade, mais uma vez o MLB recorreu ao apoio da equipe do programa Natureza Política e da VINA, que se efetivou por meio de avaliação técnica e de disponibilização de máquina, operador e material drenante.

Um fato importante que vale relatar se refere às ações realizadas durante a pandemia, empreendidas pelo movimento junto aos moradores das ocupações, sem a participação e o apoio da universidade e da empresa, para a retirada de lixo de pontos críticos do vale, com instalação de lixeiras e de mobiliário urbano e plantio de mudas nativas. Dessa vez, o movimento acionou o poder público para a disponibilização de máquinas e operadores.

Avalia-se que a rede de parcerias para a construção do Parque das Ocupações vem se configurando sob diversos formatos, desde situações nas quais o assistencialismo foi urgente e necessário, como no episódio das chuvas de janeiro, passando por momentos de interação e mobilização significativa, até por ações autônomas, que reforçam a percepção sobre as práticas do cuidado, que são presentes no território desde sempre, mas que foram sendo atualizadas ao longo dos anos, inclusive, na incorporação da pauta ambiental no discurso e na prática do MLB. 


\section{Considerações finais}

Diante da inquietação de se investigar contraposições aos processos de subjetivação presentes na racionalidade neoliberal, foram mapeadas práticas cotidianas nas ocupações urbanas autoconstruídas do Barreiro, que têm o cuidado, o compartilhamento e a reprodução da vida como centrais. Reconhecer essas práticas como pistas importantes para a construção de outras condutas, implicou em subversões de ordem metodológica e epistemológica, na busca não de uma idealização e de uma romantização dessas práticas, mas de uma postura nãocolonial sobre elas, entendendo-as como r-existências potentes na produção daquele território.

Além disso, o reconhecimento de vários atores, inclusive os não-humanos, reforçou propostas urbanísticas para o território a partir dos híbridos mapeados, como a desenvolvida para a arborização, que aproximou as duas pautas, ambiental e por moradia, na identificação de potenciais cuidadores para as árvores plantadas. Ainda, a incorporação da pauta ambiental pelo MLB pode ser percebida como resultado do processo do Parque e aponta para ações futuras integradas e não-colonizadas.

Para efetivar as intervenções realizadas, foi preciso a construção de uma rede de parceiros, composta por moradores e movimento social, academia, poder público e iniciativa privada e também dos não-humanos. En- 
tretanto, como mencionado no tópico 2, os grupos não são comunidades a priori e as convergências não são da ordem do natural e espontâneo, mas construídas coletivamente, diariamente. Descompassos fazem parte dessa construção e eles surgem por diversos motivos. Alguns são superados, mas, todo o tempo, surgem novos e é possível dizer que o maior deles continua sendo aqueles relativos ao agenciamento transversal das expectativas de atores tão diferentes - universidade, comunidade socialmente vulnerável, movimento social de luta, empresa, poder público, agentes não-humanos.

A tentativa é de convergir para a construção de um objetivo comum, sem, contudo, apagar as várias diferenças postas e as singularidades de cada um. Nesse sentido está sendo primordial conhecer, entender e agir com esses diversos atores, a partir das pesquisas e mapeamentos empreendidos, do trabalho da extensão universitária, da promoção de encontros entre os diversos dos projetos e construções realizados.

\section{Agradecimentos}

Agradecemos ao apoio dos nossos programas e projetos; ao Conselho Nacional de Desenvolvimento Científico e Tecnológico (CNPq), à Pró-Reitoria de Pesquisa (PRPq) da UFMG; à Pró-Reitoria de Extensão (PROEX) da UFMG. Aos moradores e moradoras das Ocupações Eliana Silva 
e Paulo Freire, ao Movimento de Luta nos Bairros, Vilas

e Favelas (MLB), ao departamento socioambiental da VINA e à Companhia de Saneamento de Minas Gerais (COPASA).

\section{Referências}

BARTHES, Roland. Como viver juntos: simulações romanescas de alguns espaços cotidianos. São Paulo: Martins Fontes, 2003.

COSTA, Heloisa Soares de Moura; PEIXOTO, Mônica Campolina Diniz. Dinâmica imobiliária e regulação ambiental: uma discussão a partir do eixo-sul da Região Metropolitana de Belo Horizonte. Rev. bras. estud. popul., São Paulo, v. 24, n. 2, p. 317-336, Dez. 2007. Disponível em: <http://www.scielo.br/scielo.php?script=sci_arttex t\&pid=S010230982007000200009\&lng =en\&nrm=iso $>$. Acesso em: 10 jun. 2020.

DARDOT, P., LAVAL, C. A nova razão do mundo. Ensaio sobre a sociedade neoliberal. São Paulo: Boitempo, 2016.

ESCOBAR, Arturo. De baixo, pela esquerda e com a terra. 2016. Disponível em:<https://singa2017.wordpress. com/2016/12/01/de-baixo-pela-esquerda-e-com-a-terra/>.

O lugar da natureza e a natureza

do lugar: globalização ou pós-desenvolvimento? Buenos 
Aires: CLACSO, 2005.

FREIRE, P. A pedagogia da autonomia: saberes necessários à prática educativa. São Paulo: Paz e Terra, 1996. FOUCAULT, Michel. O Nascimento da Biopolítica. São Paulo: Editora Martins Fortes, 2008.

Microfísica do Poder. Rio de Janeiro:

Edições Grall, 1979.

HISSA, Cássio. Saberes ambientais: desafios para o conhecimento disciplinar. Belo Horizonte: Editora UFMG, 2008.

HAESBAERT, Rogério. 0 mito da desterritorialização: do fim dos territórios à multiplicidade. Rio de Janeiro: Bertrand, 2009.

MIGNOLO, Walter. Histórias locais/projetos globais. Belo Horizonte: editora UFMG, 2004.

POLANYI, Karl. A grande transformação: as origens de nossa época. Fanny Wrabel. - ed.- Rio de Janeiro: Compus, 2000.

STENGER, Isabelle. A invenção das Ciências Modernas. São Paulo: Editora 34, 2002. 